\title{
Conceptual approach for an in-line quality control system in Additive Manufacturing Powder Bed Fusion processes
}

\author{
Simina Fulga ${ }^{1,2, *}$, Arjana Davidescu ${ }^{2}$, and Ira Effenberger $^{1}$ \\ ${ }^{1}$ Fraunhofer Institute for Manufacturing Engineering and Automation IPA, Department Machine \\ Vision and Signal Processing, 70569 Stuttgart, Germany \\ ${ }^{2}$ Politehnica University Timisoara, Mechatronics Department, 300222 Timisoara, Romania
}

\begin{abstract}
Additive Manufacturing is one of the genuine hopes for the forth industrial revolution since digital data is controlling the whole layered production process. At the same time the geometric freedom and tool-free production assures a high degree of individualisation. But to be the driving force behind a new industrial revolution, a qualification of additive manufacturing processes is necessary so that the resulting products meet the required quality and safety standards in the different fields of application such as in handling technology or medical technology. This paper will discuss a conceptual approach for the development of an in-line quality control system in Additive Manufacturing Powder Bed Fusion processes using the example of the Selective Laser Sintering process.
\end{abstract}

\section{Introduction}

Additive Manufacturing (AM) Powder Bed Fusion (PBF) processes, one of the seven categories of AM processes, as defined in ISO/ASTM 52900-15[1], open up new possibilities in terms of geometrically and functionally optimised parts and assemblies. At the same time the geometric freedom and tool-free production assures a high degree of individualisation. However, can AM technologies really find their way into industrial environments? Can highly customized unique parts be additively produced as efficiently as conventional mass-produced parts? Can we additively manufacture batch size 1 products? Nevertheless the unpredictable quality and reliability of additive manufactured parts, due to e.g. geometrical deviations, part distortions, delamination as well as the lack of reproducibility, are underlining the fact that Quality Control (QC) and Quality Assurance (QA) must be further developed in order to manufacture a product which is "fit for purpose" and "right first time“".

As far as industrial applications of additively manufactured parts are concerned, ranging from the medical field (e.g. patient specific parts, implants, instruments and even organs) to the automotive industry (e.g. ventilation inlet, see Fig.1.), the two most important AM PBF technologies are the Selective Laser Sintering (SLS) and Selective Laser Melting (SLM).

\footnotetext{
*Corresponding author: Simina.Fulga@ipa.fraunhofer.de
} 


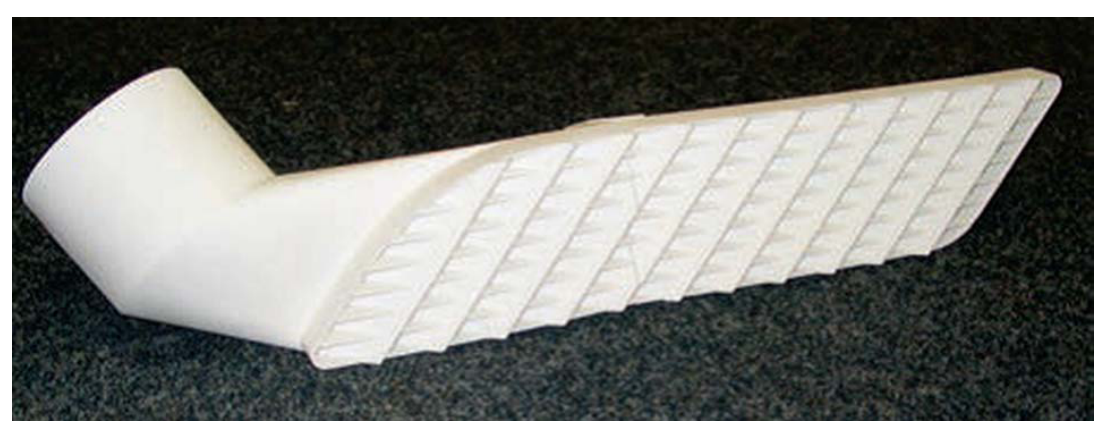

Fig. 1. Ventilation inlet for the automotive industry [source: RTC University Duisburg-Essen].

The scientific needs for the QA chain of the SLS and SLM product manufacturing process can be summarised with respect to:

- Data-management: at this time there is no uniform data management. There are no standards that define the digital process chain for the different additive manufacturing facilities. Thus, for example, geometrical and process data are widely mixed in machinespecific formats. There is no possibility to perform a recording of the entire product manufacturing process for each part produced. Therefore, the reproducibility is not provided in the AM production.

- Real-production integration: today additive production facilities are usually independently working laboratory machines that are not integrated in a process chain. The process variables are partly recorded during the manufacturing process but not long-term logged.

- 3D-input-data and their effect on the quality of the AM parts: the Surface Tessellation Language (STL) format is the de facto industry standard, despite recent data formats such as "Additive Manufacturing File Format" (AMF) or the "3D Manufacturing Format" (3MF). Up to date, there are no standards or guidelines that describe and/or specify the required quality characteristics for the STL models. 3D input data affect massively the quality of the final product and must therefore be suitable prepared with the requirements of a production process [2]. This is often carried out by manual, time and costs spending, post processing steps.

- In-line $Q C$ and in-process optimization: by the parts, components or objects which are additively manufactured, quality problems appear during the production process caused by different factors. These are leading to vulnerabilities, fractures, or product failure [3]. There is no AM in-line approach which at the same time:

- can detect and classify comprehensively such errors,

- monitors and optimizes in real-time the AM processes,

- offers a complete quality report of the produced part, and

- can abort the production process in extreme cases.

In this context the scope of this paper is to develop a conceptual approach for an in-line QC system for SLS processes; SLS technology-based additive systems being nowadays the ideal solution for the production of parts with integrated functionality and even for low series production. 


\section{In-line QC of SLS processes}

\subsection{QC in AM PBF processes}

Up to now the major international machine builders for AM systems are supporting completely insufficiently the efforts of the users in terms of Quality Management (QM) and QA for AM production applications. Only the aerospace industry has driven, with extremely great effort, individual solutions for the manufacturing of metallic components without finally debating this topic.

For a future industrial acceptance of the AM processes, as standard production processes, appropriate activities towards worldwide Quality Standards were started by ISO and ASTM.

The manufacturer itself is blindly dependent, at least on the equipment and on the powder quality. As service provider, always responsible towards the client for the expected quality, he has no direct control of the quality and the reproducibility of the produced parts. Therefore an overall in-line QC system during the manufacturing process is more than essential, not only for the manufacturer itself but also for all end users of the AM parts.

Typical errors and quality problems that may occur in the additive production and which especially affect the additive manufactured end-products are:

- lack of geometric accuracy of the parts which is dependent on e.g. the raw material conditioning, the temperature control, the laser offset, the cooling process, the layer thickness or the slicing procedure;

- component distortions caused e.g. by the cooling process and the temperature control in the machine;

- fluctuations in the quality depending on the placement of the parts in the space of the machine;

- reduced mechanical strength: deviating density through e.g. too low laser power or too high laser speed;

- surface defects: aged material, unsuitable material mixture, contamination by extraneous substances;

- closure of narrow or deep channels and holes in the component by partial melting of the marginal zone, dependent on the geometry.

\subsection{Tasks for the in-line QC system}

Starting from the defects and failures having an appearance during the manufacturing process [4], the future overall tasks for an in-line QC system for the SLS processes are:

- to identify all in-line defects and failures presented in Table 1, and

- to collect, during the additive process, all quality information in a part protocol.

Table 1. In-line defects and failures during AM PBF processes using the example of SLS [4].

\begin{tabular}{|c|c|}
\hline Quality influencing factors & $\begin{array}{c}\text { In-line defects and failures during the SLS process } \\
\text { inappropriate layers' adhesion, geometrical layer and } \\
\text { part distortions, deposits on laser window }\end{array}$ \\
\hline deposits on laser window & impurities in layer \\
\hline impurities & $\begin{array}{c}\text { inappropriate layers' adhesion, geometrical layer and } \\
\text { part distortions, melting of the edge zone depending on } \\
\text { the geometry, porosity }\end{array}$ \\
\hline laser and optical system & inconstant temperature \\
\hline temperature control & melting of the part, black sintered \\
\hline inert gas supply & streaky, scaly powder layer \\
\hline wear parts (e.g. seals, material supplier) &
\end{tabular}




\begin{tabular}{|c|c|}
\hline \multirow[b]{2}{*}{ wear parts (e.g. seals, material supplier) } & tilted layer geometry \\
\hline & layers' overlapping, layers' sintering failed \\
\hline \multirow{2}{*}{ powder application performance } & inhomogeneity of the layer thickness \\
\hline & density variation of the powder layer \\
\hline scaling & $\begin{array}{l}\text { geometrical deviations and distortions of the sintered } \\
\text { layer }\end{array}$ \\
\hline tolerances & geometrical deviations of the sintered layer \\
\hline beam offset & $\begin{array}{l}\text { geometrical deviations and distortions of the sintered } \\
\text { layer }\end{array}$ \\
\hline low scan speed & porosity, inhomogeneity \\
\hline surface roughness & layer and part surface roughness \\
\hline grain shape and grain size distribution & different grain sizes, grain shapes levels \\
\hline $\begin{array}{l}\text { thermal properties like melting point and } \\
\text { recrystallization }\end{array}$ & $\begin{array}{l}\text { inconstant temperature on sintering point, } \\
\text { inappropriate layers' adhesion }\end{array}$ \\
\hline type and mesh size of sieve & different grain size, inhomogeneity of the powder layer \\
\hline resolution of STL file & high surface roughness \\
\hline part orientation & part and layer orientation failure \\
\hline laser power & $\begin{array}{l}\text { inappropriate layers' adhesion, geometrical layer and } \\
\text { part distortions, melting of the edge zone depending on } \\
\text { the geometry, layer porosity }\end{array}$ \\
\hline scan, sintering speed & inconstant sintering speed \\
\hline scan, sintering line & scan line deviation \\
\hline temperature profile & $\begin{array}{l}\text { inconstant temperature on sintering point, } \\
\text { inappropriate layers' adhesion }\end{array}$ \\
\hline layer thickness & variation of layer thickness, inhomogeneity \\
\hline hatch distance & $\begin{array}{c}\text { inappropriate hatch distance, inappropriate layers' } \\
\text { adhesion }\end{array}$ \\
\hline atmosphere & melting of the part, black sintered \\
\hline skywriting & $\begin{array}{l}\text { skywriting length variations, melting of the edge zone, } \\
\text { geometrical layer and part distortions }\end{array}$ \\
\hline
\end{tabular}

In order to develop a conceptual approach for an in-line QC system it is necessary to rank the quality influencing factors; their associated in-line defects and failures being the basis for correction of the failures in SLS processes with respect to the quality aspects.

For the ranking of the probability and severity of the quality influencing factors and of their corresponding effects [4], respectively of the in-line defects and failures, at least two factors are necessary and should be taken into account: their occurrence frequency and the sunk costs directly implicated. These two factors, especially the occurrence frequency, are strongly depending on the AM machine and on the material, the feedstock used. Therefore these two factors cannot be exactly determined for all AM PBF processes, but can be approximated for particular AM machines based on an e.g. Design of Experiments (DoE) approach.

At Fraunhofer IPA a DoE has been implemented in order to generate clear-cut conclusions for the ranking of the frequency of the in-line defects and failures. The parts' production process on a SLS machine has been monitored over a determined period of time. The overall defects and failures occurred over the screening period have been logged as well as their associated quality influencing factors and effects [4]. Thus the occurrence frequency of the quality influencing factors and their associated in-line defects and failures has been established. For each defect and failure logged over the screening period, the sunk costs in percent of one build cycle have been determined. For the sunk costs' factor the following data have been used: the year turnover of a fully loaded SLS production machine (newest generation) is about 1 Million $€$, calculated over an average of: 100 builds per year, with 40 parts per build and a part price of $250 €$; one build having a value of about $10.000 €$. 
The ranking of the top in-line defects, to be identified by the in-line QC system, is presented in Table 2. The criteria for the ranking position were established taking into consideration two factors: the normalised value of the frequency of defects in percent of build cycles $\left(F_{l}\right)$, and the normalised value of the implicated sunk costs, in percent of one build cycle turnover $\left(F_{2}\right)$. The ranking scores $R_{s}$ have been determined using the following function:

$$
R_{S}=\left(w_{1} * F_{1} / F_{1 \max }\right)+\left(w_{2} * F_{2} / F_{2 \max }\right)
$$

where $w_{1}=2$ and $w_{2}=1$ are the assigned weights, and $F_{x \max }$ are the maximal values of the factors.

The interval of ranking scores has been split up in three. The ranking position values from Table 2 represent the interval to which the associated ranking score belongs to.

Table 2.Ranking of the top in-line defects to be identified by the in-line QC system.

\begin{tabular}{|c|c|c|c|c|}
\hline $\begin{array}{l}\text { Ranking } \\
\text { position }\end{array}$ & $\begin{array}{l}\text { Frequency } \\
\text { of defectsin } \\
\text { percent of } \\
\text { build cycles } \\
\quad\left(F_{l}\right)\end{array}$ & $\begin{array}{c}\text { Sunk } \\
\text { costs in } \\
\text { percent of } \\
\text { one build } \\
\text { cycle } \\
\text { turnover } \\
(F 2)\end{array}$ & $\begin{array}{c}\text { Quality } \\
\text { influencing factors, } \\
\text { faults related, } \\
\text { logged over the } \\
\text { screening time }\end{array}$ & $\begin{array}{c}\text { In-line defects to be identified } \\
\text { by the in-line QC system } \\
\Leftrightarrow \text { tasks of the in-line QC } \\
\text { system }\end{array}$ \\
\hline 1 & $<10 \%$ & $\leq 100 \%$ & $\begin{array}{l}\text { deposits on laser } \\
\text { window }\end{array}$ & $\begin{array}{c}\text { inappropriate layers' adhesion, } \\
\text { geometrical layer and part } \\
\text { distortions, deposits on laser } \\
\text { window } \\
\end{array}$ \\
\hline 2 & $<15 \%$ & $<25 \%$ & impurities & impurities in layer \\
\hline 1 & $<10 \%$ & $\leq 100 \%$ & $\begin{array}{l}\text { laser and optical } \\
\text { system }\end{array}$ & $\begin{array}{l}\text { inappropriate layers' adhesion, } \\
\text { geometrical layer and part } \\
\text { distortions, melting of the edge } \\
\text { zone depending on the } \\
\text { geometry, porosity }\end{array}$ \\
\hline 2 & $<2 \%$ & $<90 \%$ & temperature control & inconstant temperature \\
\hline 2 & $<3 \%$ & $<50 \%$ & inert gas supply & $\begin{array}{l}\text { melting of the part, black } \\
\text { sintered }\end{array}$ \\
\hline 1 & $<5 \%$ & $100 \%$ & $\begin{array}{l}\text { wear parts: material } \\
\text { supplier }\end{array}$ & streaky, scaly powder layer \\
\hline 1 & $<5 \%$ & $100 \%$ & $\begin{array}{l}\text { wear parts: tilted } \\
\text { build platform }\end{array}$ & tilted layer geometry \\
\hline 1 & $<5 \%$ & $100 \%$ & $\begin{array}{l}\text { wear parts: build } \\
\text { platform get stuck } \\
\text { or lose the high } \\
\text { information because } \\
\text { defects of the } \\
\text { stepper motor } \\
\end{array}$ & $\begin{array}{c}\text { layers' overlapping, layers' } \\
\text { sintering failed }\end{array}$ \\
\hline 1 & $<7 \%$ & $\leq 90 \%$ & $\begin{array}{l}\text { powder application } \\
\text { performance: } \\
\text { inhomogeneity of } \\
\text { the generated } \\
\text { powder layer } \\
\end{array}$ & $\begin{array}{c}\text { inhomogeneity of the layer } \\
\text { thickness }\end{array}$ \\
\hline 2 & $<5 \%$ & $<60 \%$ & $\begin{array}{l}\text { powder application } \\
\text { performance: } \\
\text { density variation of } \\
\text { the powder layer }\end{array}$ & $\begin{array}{l}\text { density variation of the powder } \\
\text { layer }\end{array}$ \\
\hline
\end{tabular}




\begin{tabular}{|c|c|c|c|c|}
\hline 3 & $<1 \%$ & $<50 \%$ & $\begin{array}{l}\text { scaling: scaling } \\
\text { factor variations }\end{array}$ & $\begin{array}{l}\text { geometrical deviations and } \\
\text { distortions of the sintered layer }\end{array}$ \\
\hline 3 & $<1 \%$ & $<50 \%$ & $\begin{array}{l}\text { tolerances: } \\
\text { inadequate } \\
\text { tolerances }\end{array}$ & $\begin{array}{l}\text { geometrical deviations of the } \\
\text { sintered layer }\end{array}$ \\
\hline 1 & $<20 \%$ & $\leq 100 \%$ & $\begin{array}{l}\text { improper beam } \\
\text { offset }\end{array}$ & $\begin{array}{l}\text { geometrical deviations and } \\
\text { distortions of the sintered layer }\end{array}$ \\
\hline 2 & $<8 \%$ & $\leq 80 \%$ & low scan speed & porosity, inhomogeneity \\
\hline 1 & $<20 \%$ & $\leq 75 \%$ & surface roughness & $\begin{array}{c}\text { layer and part surface } \\
\text { roughness }\end{array}$ \\
\hline 1 & $<10 \%$ & $\leq 90 \%$ & $\begin{array}{l}\text { grain shape and } \\
\text { grain size } \\
\text { distribution }\end{array}$ & $\begin{array}{l}\text { different grain sizes, grain } \\
\text { shapes levels }\end{array}$ \\
\hline 1 & $<20 \%$ & $\leq 100 \%$ & $\begin{array}{l}\text { thermal properties } \\
\text { like melting point } \\
\text { and recrystallization }\end{array}$ & $\begin{array}{c}\text { inconstant temperature on } \\
\text { sintering point, inappropriate } \\
\text { layers' adhesion }\end{array}$ \\
\hline 2 & $<3 \%$ & $\leq 75 \%$ & $\begin{array}{l}\text { type and mesh size } \\
\text { of sieve }\end{array}$ & $\begin{array}{c}\text { different grain size, } \\
\text { inhomogeneity of the powder } \\
\text { layer }\end{array}$ \\
\hline 3 & $<3 \%$ & $\leq 25 \%$ & part orientation & $\begin{array}{l}\text { part and layer orientation } \\
\text { failure }\end{array}$ \\
\hline 1 & $<20 \%$ & $\leq 100 \%$ & laser power & $\begin{array}{l}\text { inappropriate layers' adhesion, } \\
\text { geometrical layer and part } \\
\text { distortions, melting of the edge } \\
\text { zone depending on the } \\
\text { geometry, layer porosity }\end{array}$ \\
\hline 1 & $<2 \%$ & $\leq 100 \%$ & $\begin{array}{c}\text { scan, sintering } \\
\text { speed }\end{array}$ & inconstant sintering speed \\
\hline 1 & $<2 \%$ & $\leq 100 \%$ & scan, sintering line & scan line deviation \\
\hline 1 & $<20 \%$ & $\leq 100 \%$ & temperature profile & $\begin{array}{c}\text { inconstant temperature on } \\
\text { sintering point, inappropriate } \\
\text { layers' adhesion }\end{array}$ \\
\hline 2 & $<2 \%$ & $\leq 90 \%$ & layer thickness & $\begin{array}{c}\text { variation of layer thickness, } \\
\text { inhomogeneity }\end{array}$ \\
\hline 3 & $<1 \%$ & $\leq 25 \%$ & hatch distance & $\begin{array}{l}\text { inappropriate hatch distance, } \\
\text { inappropriate layers' adhesion }\end{array}$ \\
\hline 2 & $<3 \%$ & $<70 \%$ & $\begin{array}{l}\text { atmosphere: burning } \\
\text { of the layer }\end{array}$ & $\begin{array}{c}\text { melting of the part, black } \\
\text { sintered }\end{array}$ \\
\hline 3 & $<1 \%$ & $<50 \%$ & skywriting & $\begin{array}{l}\text { skywriting length variations, } \\
\text { melting of the edge zone, } \\
\text { geometrical layer and part } \\
\text { distortions }\end{array}$ \\
\hline
\end{tabular}

\subsection{Conceptual approach for solving the tasks of an in-line QC system}

In order to develop a conceptual approach, the ranked tasks for the in-line QC system have been classified considering the AM PBF production steps. The results are presented in Table 3.

Table 3. In-line defects to be identified by the QC system during the AM PBF production steps $\Leftrightarrow$ basis for a firm foundation of a conceptual approach for an in-line QC system.

\begin{tabular}{|c|c|}
\hline $\begin{array}{c}\text { AM production } \\
\text { steps }\end{array}$ & $\begin{array}{c}\text { In-line defects to be identified by the in-line QC system } \\
\Leftrightarrow \text { tasks of the in-line QC system (ranking position) }\end{array}$ \\
\hline \multirow{2}{*}{ During all steps } & deposits on laser window (1) \\
\cline { 2 - 2 } & inconstant temperature (2) \\
\hline
\end{tabular}




\begin{tabular}{|c|c|}
\hline \multirow{6}{*}{$\begin{array}{l}\text { After each powder } \\
\text { layer application }\end{array}$} & streaky, scaly powder layer (1) \\
\hline & layer porosity (2) \\
\hline & variation of layer thickness(2) \\
\hline & density variations of the powder layer (2) \\
\hline & impurities in powder layer(2) \\
\hline & different grain size $(2)$ \\
\hline \multirow{7}{*}{$\begin{array}{l}\text { During sintering } \\
\text { process of the powder } \\
\text { layers }\end{array}$} & inconstant temperature on sintering point (1) \\
\hline & melting of the edge zone depending on geometry (1) \\
\hline & inconstant sintering speed (1) \\
\hline & scan line deviation (1) \\
\hline & melting of the part, black sintered (2) \\
\hline & check the hatch distance (3) \\
\hline & skywriting length check (3) \\
\hline \multirow{6}{*}{$\begin{array}{l}\text { After sintering of } \\
\text { each powder layer }\end{array}$} & layers' overlapping, layers' sintering failed (1) \\
\hline & inappropriate layers' adhesion (1) \\
\hline & layer and part surface roughness (1) \\
\hline & geometrical deviations and distortions of the sintered layer (1) \\
\hline & layer porosity (2) \\
\hline & $\begin{array}{l}\text { layer/part orientation within the build volume, only after sintering the } \\
\text { first layer (3) }\end{array}$ \\
\hline \multirow{3}{*}{$\begin{array}{l}\text { After part is finished } \\
\text { sintered }\end{array}$} & geometrical deviations and distortions of the part (1) \\
\hline & porosity analysis of the part over all layers (1) \\
\hline & part surface roughness (1) \\
\hline
\end{tabular}

\subsubsection{Hardware platform: appropriate technologies and sensors}

The hardware (HW) platform must be a modular one, in order to solve all of the in-line QC system tasks identified. The modularity of the HW platform will allow in the future:

- to easily add other sensors in order to solve new quality issues that will appear with the development of the AM PBF machines

- to easily adapt the system to other AM PBF processes

- to allow a data fusion of the sensors on the Software (SW) side of the future system

The appropriate technologies, respectively the sensors' requirements for the multisensor analysis and field monitoring, have been identified regarding the identified tasks during the AM PBF production steps (see Table 3.) and the best price/performance ratio.

In Table 4all technologies are summed up in principle, in order to solve the classified tasks, exemplary for a SLS machine (Fa. EOS). Three IQCSM (In-line Quality Control System Modules) will be necessary. For exact requirements of the IQCSM components the inspected field, the working distance and the identified tasks must be grasped.

Table 4.Technologies and sensors necessary to solve all the classified tasks- exemplary for a SLS machine (Fa. EOS).

\begin{tabular}{|c|c|l|l|}
\hline $\begin{array}{c}\text { IQCSM } \\
\text { no. }\end{array}$ & $\begin{array}{c}\text { Sensors for the } \\
\text { data and signal } \\
\text { acquisition }\end{array}$ & \multicolumn{1}{|c|}{ Tasks } & IQCSM $\boldsymbol{n}$ components \\
\hline \multirow{1}{*}{1} & $\begin{array}{c}\text { Machine Vision } \\
\text { System }\end{array}$ & $\begin{array}{l}\text { must acquire during all AM } \\
\text { production steps an image of the laser } \\
\text { window as basis for the laser window } \\
\text { clean check }\end{array}$ & $\begin{array}{l}\text { industrial image } \\
\text { processing camera, lens, } \\
\text { appropriate illumination } \\
\text { Obs. must be integrated } \\
\text { in the machine, } \\
\text { therefore needs a } \\
\text { cooled housing }\end{array}$ \\
\hline
\end{tabular}




\begin{tabular}{|c|c|c|c|}
\hline 2 & $\begin{array}{c}\text { Machine Vision } \\
\text { System }\end{array}$ & $\begin{array}{l}\text { - must acquire after each powder layer } \\
\text { application at least one image of the } \\
\text { powder layer, for the inspection of: } \\
\text { streaky, scaly powder layer; layer } \\
\text { porosity; impurities in powder layer } \\
\text { and the powder grain size } \\
\text { - must assure during the sintering } \\
\text { process a "live stream" of the sintering } \\
\text { process for the inspection of: melting of } \\
\text { the edge zones; melting of the whole } \\
\text { layer "black sintered" } \\
\text { - must assure after sintering of each } \\
\text { powder layer at least one image of the } \\
\text { sintered layer as basis for the inspection } \\
\text { of: layers' overlapping; geometrical } \\
\text { deviations and distortions of the } \\
\text { sintered layer; porosity; layer/part } \\
\text { orientation within the build volume, } \\
\text { only after sintering the first layer } \\
\text { - must assure after the whole part is } \\
\text { finished all the images corresponding to } \\
\text { all sintered layers of the part in order to } \\
\text { reconstruct from all the } 2 \mathrm{D} \text { images the } \\
\text { 3D Real Model as basis for the } 3 \mathrm{D} \\
\text { inspection of: geometrical deviations } \\
\text { and distortions of the part on } 3 D \text { level; } \\
\text { porosity analysis of the part over all } \\
\text { layers; part surface roughness }\end{array}$ & $\begin{array}{l} \\
\\
\text { industrial image } \\
\text { processing camera, lens, } \\
\text { appropriate illumination } \\
\text { Obs. If the camera is } \\
\text { integrated in the } \\
\text { machine needs a cooled } \\
\text { housing; else must work } \\
\text { through a dedicated } \\
\text { window. }\end{array}$ \\
\hline 3 & $\begin{array}{c}\text { Thermography } \\
\text { system }\end{array}$ & $\begin{array}{l}\text { - must assure after each powder layer } \\
\text { application the necessary images for a } \\
\text { Lock-in Thermography for the } \\
\text { inspection of: homogeneity of the layer } \\
\text { thickness; density variations of the } \\
\text { powder layer; impurities in powder } \\
\text { layer } \\
\text { - must assure during the sintering } \\
\text { process of the powder layers a "live } \\
\text { stream" of images of the sintering } \\
\text { process as basis for the inspection of: } \\
\text { temperature variation on the sintering } \\
\text { point, temperature distribution; scan } \\
\text { speed variation; scan line deviation; } \\
\text { check the hatch distance and } \\
\text { skywriting length check } \\
\text { - must assure after sintering of each } \\
\text { powder layer the necessary images for a } \\
\text { Lock-in Thermographyof the sintered } \\
\text { layer for the inspection of: } \\
\text { inappropriate layers' adhesion }\end{array}$ & $\begin{array}{l} \\
\text { infrared camera, } \\
\text { appropriate excitation } \\
\text { source } \\
\text { Obs. If the camera is } \\
\text { integrated in the } \\
\text { machine needs a cooled } \\
\text { housing; else must work } \\
\text { through a dedicated } \\
\text { window. }\end{array}$ \\
\hline
\end{tabular}




\subsubsection{Design of the hardware architecture: hardware concept and interfaces}

The hardware architecture is a modular one. New hardware modules can be added to the inline QC system at any time in order to:

- adapt the system to other AM PBF machines

- solve new in-line quality tasks

The hardware concept and the corresponding interfaces are presented in Fig.2. Between the sensors identified and defined in chapter 2.2.1, respectively all the other sensors necessary for the system implementation (e.g. emergency stop button, machine door open), and between the PC, the communication is based on a Gigabit Ethernet (GigE) interface. The connection for the communication to the machine is established over a Programmable Logic Controller (PLC) based on PROFINET protocol and the connection for the Sensors (e.g. Cameras) with a GenICam (Generic Interface for Cameras) protocol. Both are GigE based protocols.

GigE compatible sensors will be connected directly over the ports of the GigE-Network Boards. The boards will have Power over Ethernet (POE) support. In this way the sensors with POE support (e.g. the machine vision systems) will be supplied with electricity directly over the standard Ethernet cables. A big advantage for the inline system: the data communication and the electricity will be assured only over one cable.

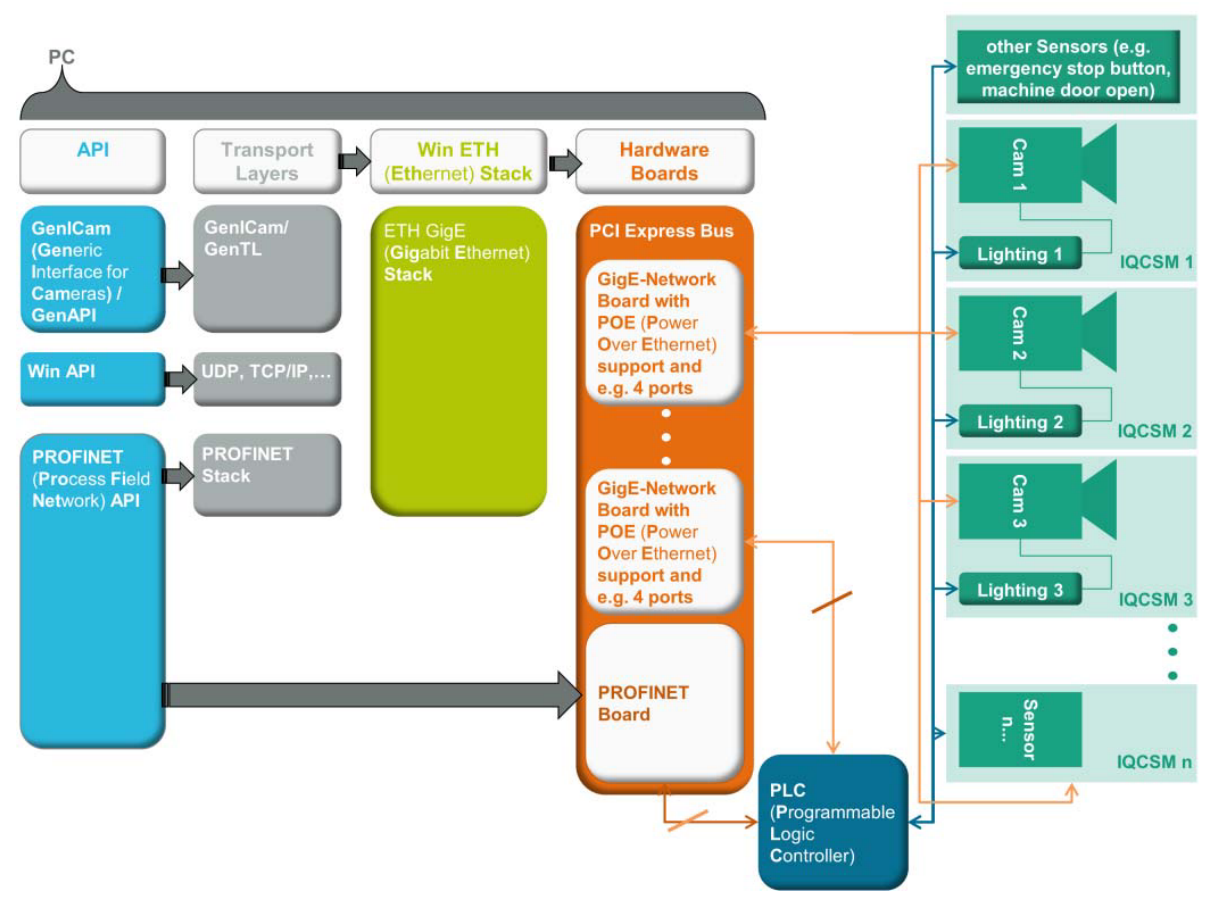

Fig. 2. Hardware concept of the modular in-line QC system for AM PBF.

The PLC, a digital computer used for the automation of the in-line QC system processes, can be connected over one port of one GigE Board or directly to a PROFINET Board. A PROFINET Board allows at least $90 \%$ of the PROFINET stack to work directly on the board. PROFINET has been described as the "all-encompassing Industrial Ethernet" since it can be used for virtually any function required in automation: discrete, process, motion, peer-to-peer integration, vertical integration, safety, and more. Because PROFINET uses standard IEEE 802.3 Ethernet, it inherently works over IEEE 802.11 wireless Ethernet. 


\subsubsection{Results}

The premises for the implementation of an in-line QC system for AM PBF processes, using the example of the Selective Laser Sintering process, have been achieved in form of a conceptual approach. Following the developed approach, the ranked tasks of the planned system will be used as basis for the determination of the technologies and sensors necessary for the hardware platform, which will than directly flow into the concept of the hardware architecture, including the corresponding interfaces.

These results constitute the basis for the development and implementation of a software platform, including an automatic data evaluation platform, for an in-line QC system for the SLS processes.

\section{Conclusions}

This paper presents a conceptual approach for the development of an in-line QC system for AM PBF processes using the example of SLS.

The obtained results, having as objective to identify and determine the technologies and sensors necessary for an overall in-line detection of defects and failures during AM PBF processes, lay a firm foundation for the development and implementation of an in-line QC system on an AM PBF machine, applied to ensure the quality of the SLS manufactured parts. This QC system will assure, aside of the up to date in-process measurements of surface temperature, residual stress and geometry [5], the in-line identification of all inprocess appearances of quality influencing factors.

Future work will be the development and implementation of a software platform, including an automatic data evaluation platform, for an in-line QC system for the SLS processes. All results achieved constitute the solid background of an in-line QC system, as basis for a future in-situ optimisation system, for the AM PBF processes.

\section{References}

1. ISO/ASTM 52900-15, Standard Terminology for Additive Manufacturing - General Principles - Terminology, ASTM International (West Conshohocken, PA, 2015)

2. J. Kroll et al., SPIE, 86500, 86500N (2013)

3. G. Kreiseler, J. Kroll, S. Fulga, I. Effenberger, Euspen Int.Conf., 1 (2014)

4. S. Fulga, A. Davidescu, I. Effenberger, CoSME'16 (to be published)

5. M. Mani, B. Lane, A. Donmez, et al., Measurement Science Needs for Real-time Control of Additive Manufacturing Powder Bed Fusion Processes (NIST Interagency/Internal Report-NISTIR 8036,2015) 